\title{
Cuidados na produção de dormentes monoblocos de concreto protendido
}

THARLLES JOSÉ SOARES FERNANDES - ENGENHEIRO CIVIL

VALEC Engenharia, Construções e Ferrovias S.A.

\section{INTRODUÇÃO}

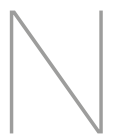

osso país carece, ainda, substancialmente de infraestrutura ferroviária. 0 desenvolvimento do modal ferroviário é capaz de reduzir os custos dos fretes, beneficiando principalmente os grandes volumes transportados a longas distâncias, que é o caso das commodities de baixo valor agregado, os grãos e os minérios, maior fonte de exportação do país. Ao mesmo tempo, reduzirá o volume de tráfego nas rodovias e consequentemente sua manutenção.

Contudo, o setor de infraestrutura ferroviária é caracterizado por projetos que, em geral, exigem uma grande aplicação de recursos, planejamento minucioso e alto controle de qualidade, principalmente na fase de execução dos empreendimentos.

Um dos grandes desafios da engenharia ferroviária nacional é conseguir produzir de maneira rápida, eficiente e com qualidade os insumos que compõem as vias férreas. Dentre esses insumos, abordaremos neste artigo os dormentes monoblocos de concreto protendido, apresentando práticas que contribuem na melhoria de sua produção e qualidade, e que evitam a ocorrência de manifestações patológicas no concreto.

Os dormentes podem ser constituídos por diversos materiais, tal como

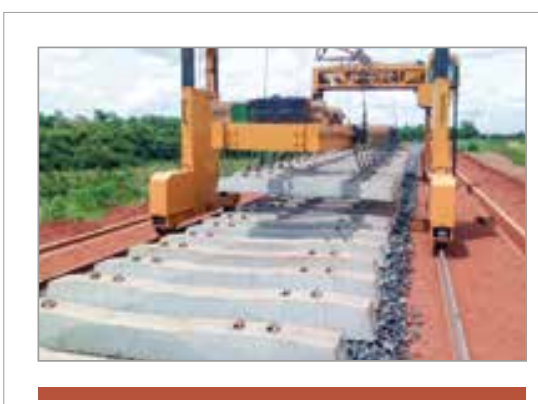

Figura 1

Registro do momento de aplicação de dormente na via com auxílio de pórtico rolante, Ferrovia Norte-Sul, Lote 5S, Minas Gerais

madeira, concreto, aço e até materiais reciclados, porém os dormentes monoblocos de concreto protendido têm a vantagem de proporcionar maior estabilidade na via, devido ao seu maior peso, que dá ancoragem, evitam deslocamentos horizontais e laterais, ocasionam mínimo impacto ambiental, têm vida útil longa, 50 anos ou mais, e têm o melhor custo-benefício.

Pelos motivos acima elencados, eles foram adotados nos empreendimentos da VALEC - Engenharia e Construção de Ferrovias S/A, empresa pública vinculada ao Ministério da Infraestrutura, responsável pela execução das obras das Ferrovias Norte-Sul (FNS) e a de Integração Oeste-Leste (FIOL).

Durante o desenvolvimento das obras da Ferrovia Norte-Sul, os técnicos a serviço da VALEC observaram procedimentos, por vezes carentes de normatização, mas com fundamento em experiências prévias e estudos científicos, capazes de resguardar o resultado da produção de dormentes monoblocos de concreto de surpresas indesejáveis.

A qualidade dos dormentes de concreto protendido é essencial para o adequado funcionamento da estrutura da via férrea. Este elemento tem por finalidade dar suporte, recebendo e transmitindo ao lastro os esforços exercidos pelo tráfego de composições que transitam pela ferrovia. Os dormentes recebem e exercem suporte aos trilhos neles fixados e mantêm constante a bitola, que é a distância fixa entre os trilhos.

Para isso, é necessário que as dimensões, no comprimento e na largura, forneçam uma superfície de apoio suficiente para que a taxa de trabalho no lastro não ultrapasse certo limite; e que sua espessura the dê a necessária rigidez, permitindo, entretanto, alguma elasticidade. Deve ainda ter: durabilidade; suficiente resistência aos esforços; permitir, com relativa facilidade, o nivelamento do lastro (socaria), na sua base; e se opor eficazmente aos deslocamentos longitudinais e transversais da via (NABAIS, 2014).

Este trabalho é uma compilação de 


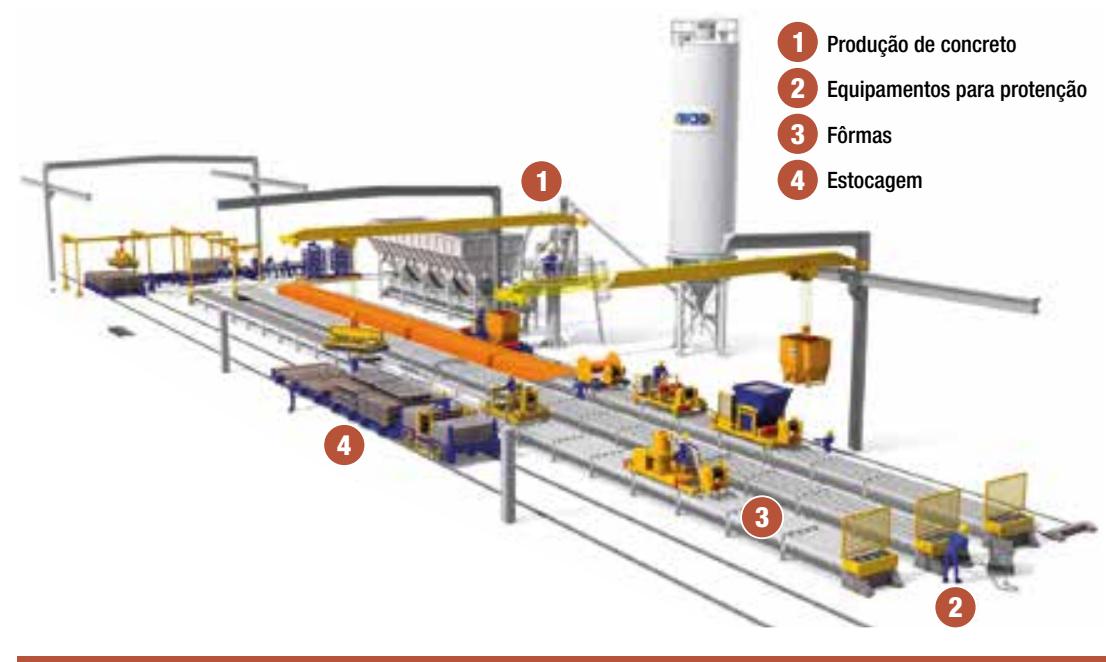

Figura 2

Layout e organização da fábrica de dormentes

Fonte: http://www.weiler.com.br/dormentes/dormentes.html (adaptado)

conhecimentos adquiridos nas fábricas itinerantes montadas ao longo das obras da Ferrovia Norte Sul, em especial no trecho entre as cidades de Ouro Verde - GO e Estrela D'Oeste - SP, conhecido como Extensão Sul (Figura 1).

Serão apresentados sumariamente alguns detalhes normativos, aprendizados e metodologias executivas utilizadas com a finalidade de contribuir ao desenvolvimento de melhorias na prática da fabricação dos dormentes de concreto. Com a visão de que o controle tecnológico não pode se limitar a ensaios laboratoriais, exalta-se a importância de que todos os responsáveis técnicos envolvidos se mantenham vigilantes em todas etapas da produção, pois, quando bem executados, estes procedimentos trazem benefícios aos executores e proprietários da obra, tanto em qualidade quanto em redução de custos e prazos, além, é claro, de garantir que os dormentes fabricados mantenham os parâmetros técnicos desejáveis durante todo seu tempo de vida útil.

\section{CONTROLE DA QUALIDADE}

Os cuidados com os dormentes monoblocos de concreto protendido devem ser observados desde o desenvolvimento do projeto, nos ensaios dos insumos utilizados e dos protótipos, bem como nas definições dos procedimentos a serem adotados durante sua produção.

O projeto estrutural dos dormentes deve atender aos parâmetros condicionantes do projeto da via permanente, em perfeita compatibilidade com os triIhos e acessórios. A escolha dos materiais componentes do dormente (aço e concreto) deve observar as condições locais da fabricação e uso. Devem ser exigidas as memórias de cálculo, deta-

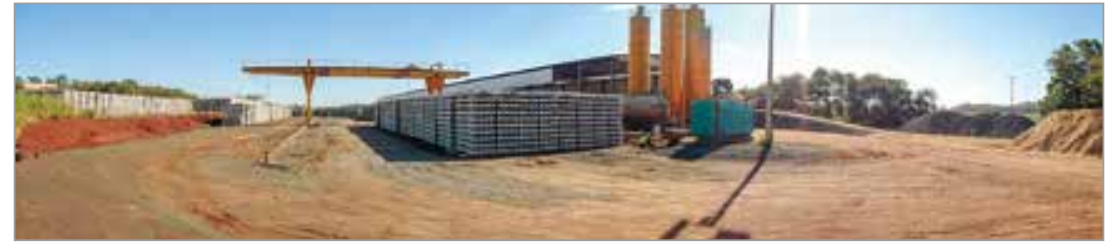

Figura 3

Vista exterior da fábrica de dormentes utilizada no Lote 5S, Minas Gerais
Ihamentos, traços do concreto e descrição dos métodos e tempos de cura.

A matéria-prima necessária à produção do concreto deve possuir as características físicas e químicas adequadas às exigências das normas da Associação Brasileira de Normas Técnicas (ABNT), as quais devem ser comprovadas por meio de ensaios laboratoriais.

Os agregados devem ser criteriosamente escolhidos, atentando-se aos testes de reatividade álcali-agregado.

O layout e a organização da fábrica de dormentes (Figura 2) devem observar a facilidade do fluxo de pessoas e equipamentos, com melhor distribuição de espaço, possibilitando o trânsito livre dos operários e fiscalização, que necessita fazer coletas de amostras dentro da fábrica, que serão submetidas a controle de qualidade. Deve-se procurar simplificar os processos de concretagem e de desmoldagem, movimentação, manuseio e estocagem dos dormentes (Figuras 3 e 4).

\section{I Formas $€$ marcaçõ $\in$ S}

Os moldes devem possuir dimensões precisas, observando as tolerâncias especificadas em norma. Os dormentes produzidos devem passar por rígido controle dimensional, a

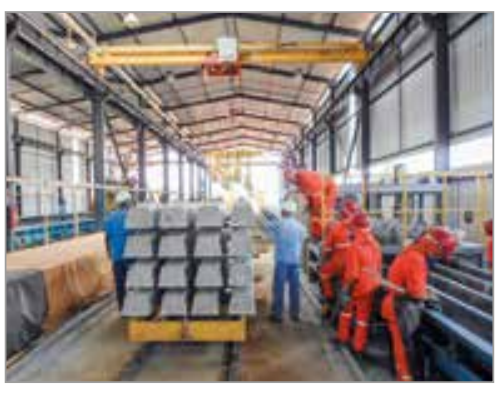

Figura 4

Interior de fábrica de dormente, Lote 2S, Goiás 

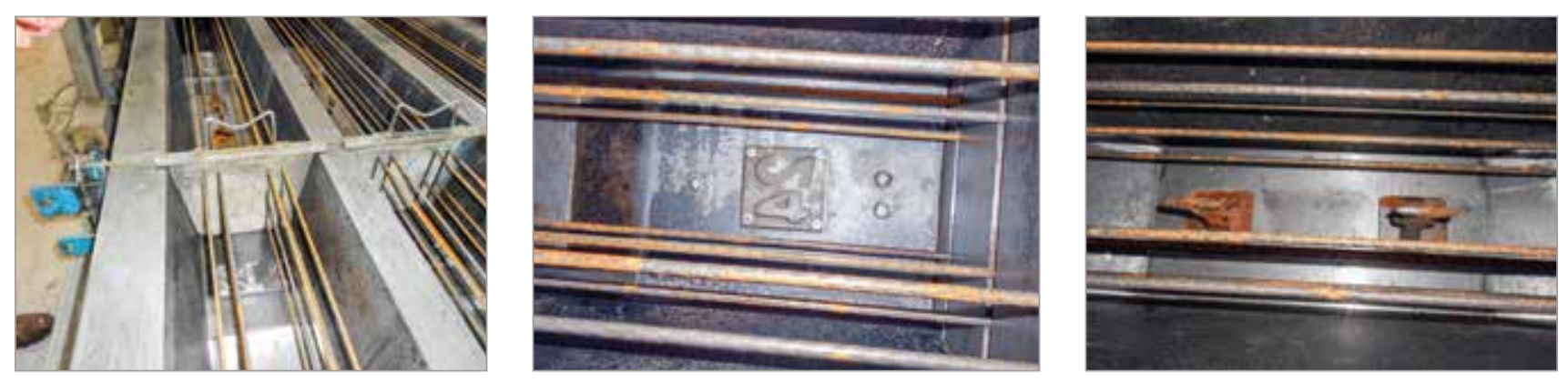

Figuras 5, 6 e 7

Detalhes das formas, dispositivo para marcações indeléveis no dormente e instalação de ombreiras, lote 2S,

Ferrovia Norte-Sul

fim de avaliar a qualidade das formas empregadas e identificar as que necessitam de substituição (Figura 5).

Os cobrimentos mínimos da armadura também devem ser observados (30 $\mathrm{mm}$ na base e $20 \mathrm{~mm}$ nas demais partes do dormente, no mínimo, ou obedecer os cobrimentos conforme ABNT NBR 6118:2014, conforme CAAClasse de Agressividade Ambiental), assim como a fiscalização deve manter-se atenta aos locais de passagem dos fios de protensão, nas abas laterais da forma, solicitando suas correções quando necessário.

Todo dormente deve possuir marcações indeléveis, produzida por "carimbos" introduzidos nos inserts das formas, antes das moldagens (Figura 6). Atualmente, as especificações de serviço determinam que todos os dormentes deverão ser identificados e conter, no mínimo, através de marcações indeléveis, na face superior, o nome do proprietário, do fabricante, mês/ano de fabricação, identificação da forma, pista e linha. A identificação da forma, pista e linha de produção interessa ao controle de qualidade na fábrica, possibilitando identificar formas que necessitam ser substituídas, através do controle dimensional do dormente.

A ABNT NBR11709, bem como as demais especificações técnicas, não obrigam a identificação indelével dos lotes dos dormentes na superfície superior, o que dificulta a identificação em campo dos dormentes que possam vir apresentar problemas após seu lançamento na via.

Entretanto, para marcação mais importante, que é a do número do lote, a VALEC adotou o procedimento de gravar na parte inferior do dormente, o que se fazia necessário, pois é através do número do lote que são realizados todos os controles tecnológicos previstos em normas realizados durante a fabricação.

Este procedimento se mostrou ainda ineficiente, pois as marcações ficam escondidas em lugar de difícil acesso após o lançamento dos dormentes em campo. A prática nos mostra que é preciso melhorar o sistema de identificação dos dormentes, pois é conhecendo o número do lote que se torna possivel rastrear todas as informações referentes aos controles tecnológicos utilizados durante o processo de produção e da sua vida útil em campo.

É importante observar o posicionamento dos dispositivos para a ancoragem dos grampos (ombreiras). Estes devem ser inseridos nas aberturas da forma somente após a passagem do desmoldante (aplicado com aspersor), assim como a armadura da peça (Figura 7).

\subsection{Protensão dos fios de aço}

O método de protensão predominantemente usado na fabricação de dormentes para a Ferrovia
Norte-Sul (trecho Ouro Verde GO - Estrela D' Oeste SP) constitui-se da aplicação de uma pré-tensão nos fios das armaduras (protensão por aderência inicial). Deste modo, os fios eram cortados em dimensão definida em projeto, medida referente ao fio pré-esticado, e ancorado nas duas extremidades (uma passiva e outra ativa). Os fios devem, obrigatoriamente, ser nervurados (Figura 8).

Alguns cuidados devem ser observados na armazenagem dos fios: o local deve ser coberto, seco e também isento de produtos que possam vir contaminá-los.

A protensão é realizada aplicando-se a carga de projeto, com tensão controlada por um manômetro, sendo conferido o respectivo alongamento previsto dos fios. Conforme especificação de serviço da Valec, os resultados da tensão aplicada e alongamento real não podem diferir entre sim em mais de 5\%.

Os conjuntos das ancoragens devem ser suficientemente resistentes para absorverem, sem deformações, os esforços provenientes do processo de protensão dos fios.

\subsection{Concretagem}

Após a etapa de protensão dos fios, o concreto é lançado nas formas, onde é adensado com o auxílio de vibradores de imersão (Figura 9). Recebe acabamento rústico na parte que ficará em contato com o lastro e também o 


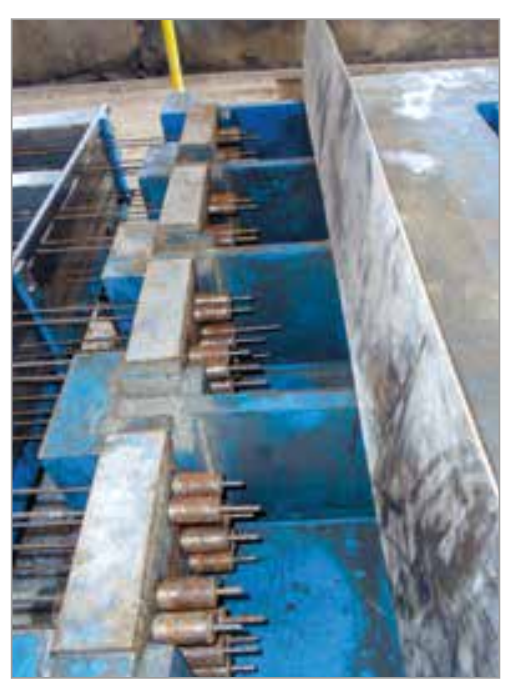

Figura 8

Pontos de ancoragem dos fios protendidos número do lote, gravado em baixo relevo, através de ferros de marcação.

O manuseio dos vibradores requer cuidado para evitar contato com as armaduras ou segregação do concreto por excesso de vibração.

Durante a concretagem, é aferido o slump e moldados os corpos de prova cilíndricos e prismáticos, que serão utilizados no controle de resistência do concreto empregado.

A base do dormente, que fica exposta na parte superior do molde, deve ser plana, entretanto deve-se ter cuidado no acabamento para que tenha a aspereza necessária, para garantir um bom atrito com o lastro.

Concluída a concretagem, a pista então é coberta com uma manta vinílica e inicia- se a cura do concreto, que poderá ser normal ou térmica.

\subsection{Cura térmica}

O processo de cura dos dormentes mais comum é realizado através de vapor, gerado por caldeiras, que circulam através de tubulações instaladas debaixo das pistas e devem ter um controle rigoroso.

O procedimento de cura exige cuidado adicional com a segurança dos trabalhadores e operação da caldeira, devendo manter-se uma rotina de treinamento, manutenção do sistema e fiscalização.

\subsection{O PROBLEMA DA ETRINGITA TARDIA}

Exposto a altas temperaturas, as reações no concreto são aceleradas, fato potencializado com a alta umidade. Estudos e observações recentes apontam que temperaturas acima de $65^{\circ}$ são favoráveis ao desenvolvimento futuro (pode levar meses ou anos) de uma manifestação patológica conhecida como etringita tardia, que se apresenta como expansão das partes do concreto e que causa desenvolvimento de fissuras devido à formação retardada da etringita mineral.

Segundo Silva (2018), a etringita é uma substância formada normalmente no processo de hidratação do concreto nos seus períodos iniciais. Existindo dois tipos principais de formação da etringita, primária e a longo prazo (secundária e tardia). A formação da etringita ocorre com a hidratação do aluminato cálcico (C3A), onde cristais se unem com compostos hidrato de silicato de cálcio $\mathrm{C} 3 \mathrm{~S} 2 \mathrm{H} 3$ (C-S-H), durante o período de pré-cura, o que não causa, no primeiro momento, nenhum dano à estrutura do concreto. Na etringita tardia, ocorre a formação de mecanismos de expansão, que rompem a resistência à tração do concreto após seu endurecimento.

A ocorrência da etringita tardia ocorre somente quando três condições estão conjuntamente presentes: presença de sulfato no cimento em excesso, alta temperatura de cura $\left(>70^{\circ} \mathrm{C}\right.$ para maioria dos autores) e suplementação de água (SILVA et al, 2018 apud MELO, 2010).

Assim sendo, considerando o co- nhecimento das condições para formação da etringita tardia, devem ser adotadas, como medidas preventivas, o controle do traço do concreto e o controle de temperatura interna do dormente.

O traço do concreto deve ter consumo máximo de cimento de $420 \mathrm{~kg} /$ $\mathrm{m}^{3}$, optando preferencialmente por cimentos com baixo teor de sulfatos em sua composição. Adicionalmente, recomenda-se a utilização da sílica ativa no concreto, pois esta adição diminui a porosidade, impedindo a infiltração de sulfatos do meio exterior e aumentando a resistência. Além disso, o uso correto de materiais pozolânicos diminui o consumo de cimento, colaborando para a redução do calor de hidratação.

O controle de temperatura no interior do dormente deve ser mantido em até $65^{\circ} \mathrm{C}$. Comumente essa temperatura é medida no interior da câmara de cura, abaixo da lona térmica, e não no interior do dormente. Este fato dissimula a aferição correta, já que o aumento da temperatura no interior da peça concretada devido ao processo de hidratação influencia a formação da etringita. Existem, no mercado, sensores de baixo custo adequados para a realização dessas medições no interior do dormente.

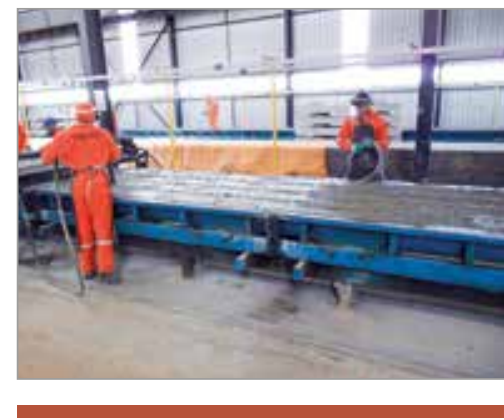

Figura 9

Vibração e acabamento no concreto, Lote 2S, Ferrovia Norte-Sul 


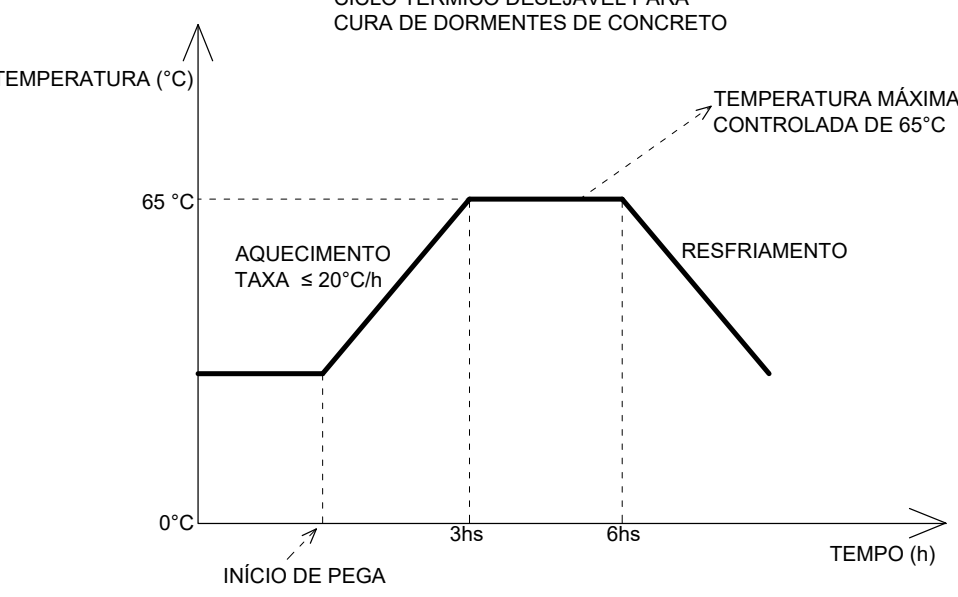

Gráfico 1

Ciclo térmico para cura de dormentes de concreto, utilizando cimento ARI. Fonte: (Autor) Adaptado das notas de aula do curso Cuidados Executivos em Obras de Concreto, ministrado na sede da VALEC pelo prof. Dr. Paulo Fernando Araújo da Silva

O Gráfico 1 demonstra o ciclo térmico desejável durante a cura dos dormentes (utilizando-se cimento de Alta Resistência Inicial - ARI), onde se observa que a taxa de aquecimento no interior do concreto não deve ser superior a $20^{\circ} \mathrm{C} / \mathrm{h}$, até o limite de $65^{\circ}$; já, o decréscimo de temperatura no resfriamento deve ocorrer com uma taxa máxima de $30^{\circ} \mathrm{C} / \mathrm{h}$, sendo desejável limitar também a $20^{\circ} \mathrm{C} / \mathrm{h}$.

Em 2017, a Valec elaborou a revisão de sua especificação de material de superestrutura $n^{\circ}$ 80-EM-031A-58-8014, adotando cuidados no controle da temperatura do concreto durante a cura térmica, conforme procedimentos preconizados na NBR 9062. Além disso, a empresa vem sistematicamente promovendo melhorias na capacitação de profissionais e adoção de medidas adicionais para evitar que este problema ocorra.

\subsection{Transferência de protensão e desforma}

Em aproximadamente seis horas, é realizado o rompimento dos corpos de prova para teste do ganho de resistência necessário. Confirmado o ganho de re- sistência exigido, inicia-se a retirada das formas com auxilio de alavancas apropriadas, evitando esforços excessivos que possam danificar a peça ou as formas.

No caso dos dormentes monoblocos protendidos por pré-tração, com aderência inicial, a operação de liberação ou de transferência da protensão não pode ser efetuada até que o concreto tenha atingido uma resistência mínima especificada em projeto. O corte dos cabos deve ser iniciado pelo lado ativo, seguindo, a partir do vão central, até as extremidades.

Outro cuidado importante, não referendado em especificações técnicas, a ser tomado após a desforma e transporte para o armazenamento, é a possibilidade de ocorrência de choque térmico no concreto, principalmente em dias frios, com chuva. Estudos mostram que uma mudança abrupta na temperatura pode ocasionar retrações imediatas no concreto e consequentemente fissuras.

Devem ser mantidas a atenção no manuseio e transporte dos dormentes, evitando impactos. Para isso, são utilizados equipamentos, como pontes rolantes, pórticos, empilhadeiras e guindastes (Figura 10).

\subsection{Ensaios laboratoriais}

O processo de fabricação de dormentes de concreto é rodeado de diversos ensaios laboratoriais obrigatórios, desde a fase inicial até a amostragem do produto finalizado. Esses ensaios devem seguir estritamente às recomendações técnicas vigentes, sendo imprescindível o acompanhamento técnico especializado.

Atualmente, a especificação técnica da VALEC, exige os seguintes ensaios:

\section{Ensaios sobre protótipo para aprovação de projeto para dormente monobloco}

Teste de Momento Positivo no Apoio do Trilho (Figura 12);

- Teste de Momento Negativo no Apoio do Trilho;

> Teste de Momento Positivo no Centro do Dormente;

> Teste de Momento Negativo no Centro do Dormente;

- Teste Dinâmico no Apoio do Trilho;

- Teste de Aderência e de Carga Final dos Elementos de Protensão (Figura 11);

Teste de Encaixe das Fixações.

\section{Ensaios para a caracterização dos materiais}

> São exigidos ensaios de caracterização de todos os componentes do concreto e no aço.

\section{Ensaios sobre corpo de prova de concreto}

Para cada lote executado, são coletados corpos de prova, em quantidade especificada, nos quais são realizados os seguintes ensaios:

- Resistência à Compressão;

> Resistência à Tração na Flexão.

\section{Ensaio dimensional e visual}

Verificação da qualidade de acabamento, marcações e se as dimensões da peça atendem as tolerâncias admitidas (Figuras 13 e 14). 


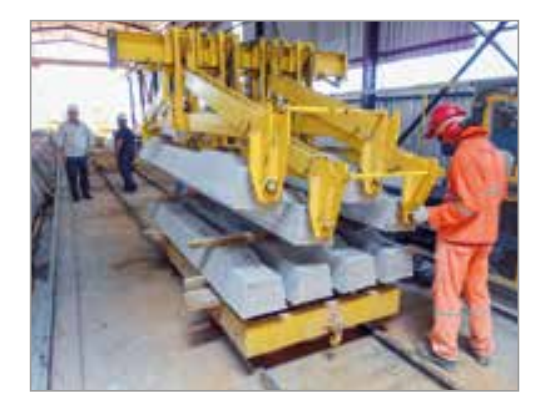

Figura 10

Manuseio de dormentes com auxílio de equipamento específico, Lote $2 \mathrm{~S}$

\section{Ensaios realizados no dormente fabricado}

São realizados os mesmos ensaios utilizados para aprovação do protótipo, em amostragem definida na especificação.

\section{CONSIDERAÇÕES FINAIS}

Os dormentes monoblocos de concreto protendido são largamente usados por suas vantagens em relação aos outros tipos de materiais disponíveis. Entretanto, conforme verificado, sua cadeia produtiva exige rigoroso controle tecnológico para se alcançar os resultados esperados.

O gasto com um bom controle de qualidade, incluindo equipamentos, laboratórios e profissionais, é muito baixo em relação ao custo total de produção. No caso de um material com alto valor agregado, como o dormente de concreto protendido, não se deve poupar recursos para o alcance de excelência na qualidade.

Pesquisas e tecnologias dos produtos e processos de qualquer sistema construtivo se desenvolvem rapidamente com o passar do tempo e as especificações técnicas que determi-

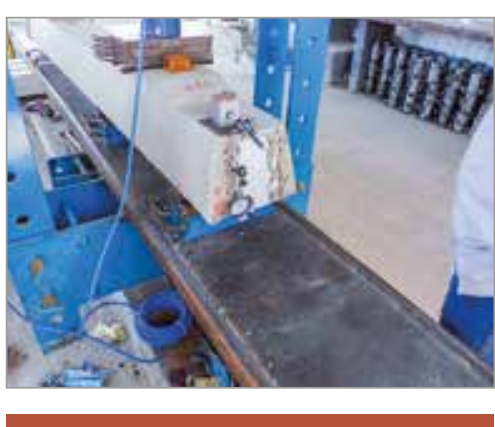

Figura 11

Ensaio de aderência do fio de aço

nam os respectivos parâmetros devem acompanhar essa evolução.

Fenômenos, como, por exemplo, a formação da etringita tardia, ainda são pouco discutidos no meio acadêmico e profissional da indústria do concreto. Sabe-se que há pouco conhecimento para evitar os efeitos relacionados à etringita tardia, outrossim notamos que seus mecanismos de formação não são simples quando comparados a outras manifestações patológicas mais recorrentes que podem surgir no concreto, sendo necessário a realização de pesquisas para a avaliação de seu impacto na durabilidade das peças de concreto.

Ao revisar a especificação de serviço $n^{\circ}$ 80-EM-031A-58-8014, confor-

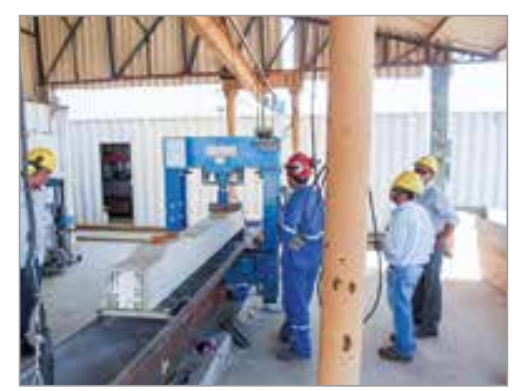

Figura 12

Ensaio de momento positivo no apoio do trilho me procedimentos descritos na atualização da NBR 9062, a VALEC deu um passo à frente na determinação de cuidados para evitar o surgimento da etringita tardia na produção de dormentes de concreto submetidos à cura a vapor. Além disso, com a coleta de dados de suas próprias obras, poderá desenvolver melhores técnicas para evitar a incidência desta e de outras manifestações patológicas.

Assim, espera-se que todo conhecimento adquirido na realização de obras de grande magnitude, qual o caso da Ferrovia Norte-Sul, colabore para evolução de procedimentos técnicos e que sejam amplamente divulgados para o meio profissional.
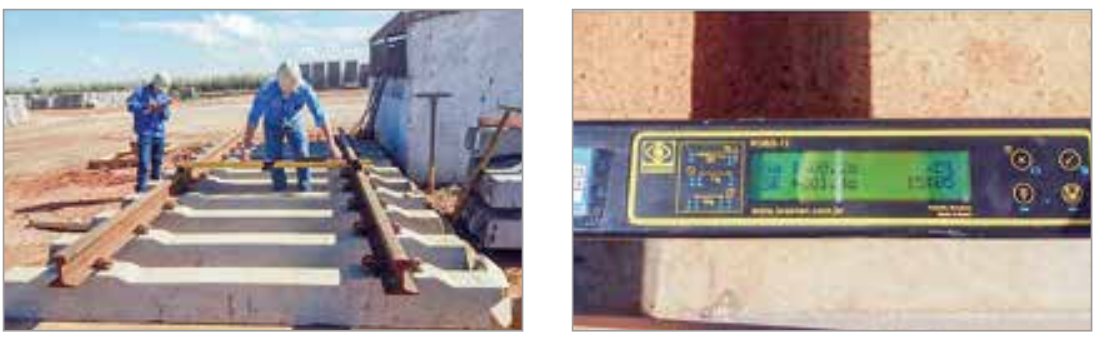

Figuras 13 e 14

Ensaio de verificação dimensional da bitola

\section{DREFERÊNCIAS BIBLIOGRÁFICAS}

[01] NABAIS, R., J.da, S. Manual básico de engenharia ferroviária. Ed. Oficina de Textos, São Paulo, 2014.

[02] SILVA, D., L. da. et, al.Considerações sobre a formação de etringita tardia (DEF). FUMEC/UFMG/Universidade do Porto, 2018. 11 p.

[03] SILVA, P., F., A. da. Notas de Aula do Curso Cuidados Executivos de Obras de Concreto.

[04] VALEC ENGENHARIA, CONSTRUÇÕES E FERROVIAS S.A. Especificação de material de superestrutura n 80-EM-031A-58-8014 Dormente monobloco de concreto protendido. rev.3. 28 p. 